Published in final edited form as:

Drug Discov Today Dis Mech. 2013 December 1; 10(3-4): e153-e158. doi:10.1016/j.ddmec.2013.10.002.

\title{
Murine Models of Polycystic Kidney Disease
}

\author{
Luis Fernando Menezes and Gregory George Germino \\ Kidney Disease Branch, National Institute of Diabetes and Digestive and Kidney Diseases, \\ National Institutes of Health, Building 10 Room 8D46, 10 Center Drive, Bethesda, MD 20892
}

\begin{abstract}
Polycystic diseases affect approximately 1/1000 and are important causes of kidney failure. No therapies presently are in clinical practice that can prevent disease progression. Multiple mouse models have been produced for the genetic forms of the disease that most commonly affect humans. In this report, we review recent progress in the field and describe some of the outstanding challenges.
\end{abstract}

\section{Introduction}

In 2003, multiple investigators in the genomics community proposed a project to knockout alleles for all mouse genes. Almost ten years later, the International Knockout Mouse Consortium now boasts of 17,400 mutant murine embryonic stem cells clones and hundreds of conditional mouse strains easily available to investigators all over the world [1]. Furthermore, new advances in gene editing techniques, such as zinc-finger nucleases (ZFNs) and transcription activator-like effector nucleases (TALENs), now hold the promise of inserting virtually any modification in the genome of mice and other vertebrates [2]. At the same time, improvements and cost reduction in high-throughput techniques for phenotypic characterization, from global analysis of gene expression, metabolic profiling to in vivo microscopy and whole animal imaging, prelude an era in which the limiting steps are likely to be data analysis and interpretation, rather than model generation. In this short review, we comment on how these developments have shaped our understanding of Polycystic Kidney Disease (PKD).

\section{Text}

\section{Using mouse models to understand/treat human disease}

Autosomal Dominant Polycystic Kidney Disease (ADPKD)—Arguably one of the nicest success stories of mouse models was the eradication of acute promyelocytic leukemia (APL) by Pandolfi's group. Over the course of almost 20 years, different gene fusions causing APL were identified and made into mouse models used to test and optimize

Corresponding Author: Luis F Menezes, MD, PhD, 301-451-9613, luis.menezes@nih.gov.

Publisher's Disclaimer: This is a PDF file of an unedited manuscript that has been accepted for publication. As a service to our customers we are providing this early version of the manuscript. The manuscript will undergo copyediting, typesetting, and review of the resulting proof before it is published in its final citable form. Please note that during the production process errors may be discovered which could affect the content, and all legal disclaimers that apply to the journal pertain. 
therapies that eventually cured the disease in clinical trials [3]. PKD patients too are now on the verge of benefiting from therapies first tried in mouse models [4].

Mutations in PKD1 ( 85\%) or PKD2 ( 15\%) cause ADPKD, the most common genetic cause of PKD, affecting 1:1000 individuals [5]. According to a two-hit genetic model, mutations on the previously normal allele of patients heterozygous for PKD1 or PKD2 mutations cause the affected cell to clonally expand and form cysts that can arise in any segment of the nephron and usually manifest in adulthood. Consistent with this model, disruption of the mouse orthologs $P k d 1$ [6,7] or $P k d 2$ [8,9] cause, among other phenotypes, embryonic lethality and bilateral kidney cyst formation starting at E15.5, whereas heterozygotes are viable and normal at birth, but may develop late-onset cysts [9]. By showing that homozygote mice had a range of phenotypes that went beyond ADPKD manifestations and that polycystin-2, the $P k d 2$ product, plays a role in right-left symmetry breaking during early embryonic development [7,10-13], these studies suggested that Pkd1/ $P k d 2$ could play additional, and non-identical, roles at different developmental stages.

Though these were important insights into PKD biology, knockout mice were not an ideal ADPKD model, as the number of kidney cysts in adult heterozygous mice was too low, and embryonic lethality severely limited the use of homozygotes. Other mouse models filled the gap: $P k d 2^{W S 25}$ has an unstable $P k d 2$ allele that undergoes frequent, though random, inactivation [12]; and conditional mice that can be inactivated at different time points/tissues were made $[13,14]$. Modeling the human disease is still not a trivial matter, however. Pkdl inactivation prior to day 14 was shown to result in massive kidney cyst formation within days, whereas inactivation after day 14 results in late-onset kidney disease that takes months to manifest [15]. Though there is some evidence to suggest that the kinetics of cyst formation could depend on the time of inactivation in humans as well [16], this is still an unresolved issue. In addition, despite the ample evidence for a two-hit model, patients homozygous for hypomorphic mutations were a theoretical possibility [5]. Human mutation studies provided supportive evidence [17], but the most compelling data came from a mouse model engineered to be homozygous for the same mutation. These mice survived into adulthood and developed progressive PKD [18]. The existence of these three models: hypomorphic, early- and late-onset poses a quite relevant question: do they share similar pathogenesis and model the same cystogenic process, or do they represent different pathways through which $P k d l$ controls normal tubular diameter? The practical implication of this question is that it is uncertain whether the three models can be interchangeably used when testing therapies.

To date, several orthologous and non-orthologous models have been used to evaluate the therapeutic efficacy of drugs altering pathways allegedly involved in PKD, mostly with positive results (Table 1). In part based on these studies, several drugs were singled out for clinical trials, but these had much more mixed results. Investigators found that mTOR inhibitors were mostly ineffective [19,20] while cAMP lowering drugs had some benefits [4,21]; Table 1). A full discussion of why clinical results may fall short of their pre-clinical counterparts is beyond the scope of this review, but a few general comments are worth making:

Drug Discov Today Dis Mech. Author manuscript; available in PMC 2014 December 01. 
- Pharmacodynamics and effective circulating doses generally are not assessed and may differ substantially between rodents and humans. For example, rapamycin was given at up to $5 \mathrm{mg} / \mathrm{kg}$ in mice [22], compared to $2 \mathrm{mg} /$ day in humans [19].

- Most therapies have been tested in early onset models with rapid cyst formation and for short duration. This is very different than the human situation where cysts form slowly over decades and where therapies will likely have to be administered for the rest of the patient's life. This is important not only when considering side effects that may be unacceptable on the long-term but also when considering drugs that may induce up/down-regulation of receptors, with potentially harmful effects in the event of sporadic drug discontinuation. Octreotide administration, for instance, was reported to induce up-regulation of some, but not all, somatostatin receptors [23].

- Outcome evaluation is also not straightforward: if the drugs don't prevent/revert cyst formation, it is unclear that small reductions in the rate of cyst expansion will have any meaningful clinical impact in patient's renal function, qualify of life, or life expectancy. It is unclear what a several week to month delay in cyst progression in rodents translates into human outcomes. In the case of everolimus, the drug was highly effective in reducing rate of cyst growth in rodents and somewhat effective in humans, but the drug had no effect on kidney function in the latter [20,24].

- As hinted at above, the selection of a rodent model is not straightforward: $p c y$ mice and the Han:SPRD polycystic rat, for instance, have been used as PKD models [25] somewhat interchangeably with orthologous ADPKD models despite the fact that neither results from mutation of either $P k d l$ or $P k d 2$. The $p c y$ line has a mutation in Nphp3, a nephronophthisis gene, which causes a mostly fibrotic disease in humans, quite distinct from ADPKD and likely to have at least partially different pathogenesis. The Han:SPRD rat has a mutation in $P k d r l$, a locus not yet associated with clinical disease in humans [26].

- To our knowledge, a systematic study on the effect and magnitude of publication biases in mouse studies is still not available. It is, however, likely not dissimilar to what is reported for meta-analysis of controlled trials: i.e. negative results, because less likely to be published, are not taken into consideration [27].

- Finally, it is worth referring to the important paper by Scott et al. [28]: when confronted with discrepancies between pre-clinical and clinical efficacies of treatments for amyotrophic lateral sclerosis, these authors demonstrated that litter effects, absence of double-blind designs with uniform endpoints, small sample sizes and violations of statistical test assumptions undermined the results. In fact, they demonstrated that random separation of control animals into "experimental" vs. "treatment" groups was likely to yield statistically significant differences when confounding variables were not controlled. This report should be mandatory reading for anyone contemplating preclinical studies using murine models. 
Autosomal Recessive Polycystic Kidney Disease (ARPKD)—Despite the challenges and limitations outlined above, it is important to note that ADPKD research has greatly benefited from animal studies. Alas, this is not true for all human cystic kidney diseases. ARPKD is caused by mutations in PKHDl, usually presents in infancy and childhood, and is characterized predominantly by dilated/cystic collecting ducts in the kidneys and ductal plate malformation and fibrosis in the liver [29]. Both PKHDI and its mouse ortholog extend over large genomic segments and include dozens of exons likely assembled into various transcripts [30-32]. Several mouse models have so far been reported and though all published models to date have liver disease, the kidney phenotype has either been lacking (disruption of exon 40 [33]; disruption of exon 4 [34]), late and/or incompletely penetrant (deletion of exon 2 [35]; deletion of exons 3 and 4 [36]; deletion of exons 1 to 3 [37]; disruption of exons 14 and 15 [38] and/or dependent on mouse strain (Germino, unpublished observation). In addition, homozygosity for a putative null Pkhdl allele created by insertion of a stop element in intron 2 only resulted in cystic disease in 3-6 month-old females [39]. It is however possible given the putative complex splicing of the locus that this is not a true null, as only probes to exons 1-18 and 60-67 were tested. In either case, whether complete deletion of $P k h d l$ results in an early ARPKD phenotype or not, it is clear that most deletions fail to consistently recapitulate the human phenotype.

Despite and partly because of their mild phenotypes, ARPKD models can be successfully used to screen for genetic or environmental modifiers likely to play roles in pathogenesis. In fact, we have previously shown that $P k h d l^{d e l 3-4 / d e l 3-4} ; \mathrm{Pkdl}^{+/-}$mutants have exacerbated

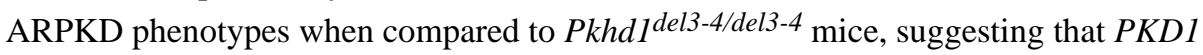
variants could be ARPKD modifiers in humans [36]. Similarly, quantifying the severity of renal and biliary phenotypes in crosses of the $c p k$ non-orthologous mouse model, Mrug et al. identified Kifl2 as a potential modifier [40]. Environmental insults are also likely to precipitate cystogenesis. Though this has not yet been shown for $P k h d l$ models, ischemia/ reperfusion [41] and toxic injury [42] in late-onset $P k d l$ models seem to accelerate cyst formation.

\section{Using rodent models to identify disease-causing human genes}

Rodent models phenocopying PKD, spontaneously found or generated in mutagenesis screens, have helped identify disease-causing human genes. The $P c k$ rat was established as a strain with a recessive form of polycystic kidney and liver disease, and the affected gene, mapped by Ward et al. to a syntenic region that contained the ARPKD human candidate region, was identified as the likely Pkhdl ortholog and used to discover the human PKHDl [32]. Though our group independently identified PKHD1 using positional cloning [31], Ward's work demonstrates the power of mouse genetics.

Two members of the never-in-mitosis A (NIMA)-related kinases (NEKs) - a group thought to coordinate microtubule-dependent processes - have been similarly first identified in spontaneous polycystic kidney mouse models, leading to the detection of disease-causing human homologs [43-46]. Nekl was first identified in mice with progressive PKD [43], subsequently shown to phenocopy and be in the candidate region for short-rib polydactyly syndrome (SRPS) type Majewski, finally leading to the recognition of NEKI as a SRPS 
gene [44]. The $j c k$ is another recessive polycystic kidney model spontaneously found and later shown to be caused by mutation in Nek8 [45]. Mutational screening of NEK8 in patients with nephronophthisis (NPHP) revealed that mutation in this gene is a rare cause of NPHP [46], one that would have been unlikely to be found, had it not been for the mouse model.

\section{Putting it all together: gene networks}

Can all these different models with overlapping phenotypes tell us something about how "cystogenes" interact? Indeed they can. The advent of powerful computational methods, associated with a plethora of mouse models, has allowed the identification of several gene networks regulating various aspects of normal kidney development/function and involved in disease processes. Though cystic kidney diseases can be grouped in mostly cystic vs. mostly fibrotic clusters, the characterization of several of the corresponding animal models and subsequent use in drug intervention studies (Table 1) suggest some pathogenic mechanisms are likely conserved (reviewed in [47]). In particular, pathways involved in the establishment of normal tubular diameter are thought to be dysregulated. Reasoning that transcription factors mutated in cystic kidney diseases could be key regulators of epithelial differentiation upstream of cystogenes, Gresh et al. showed that conditional inactivation of Hnfl $\beta$ in kidney epithelium results in cyst formation and is accompanied by down-regulation of, among others, $P k d 2$ and $P k h d 1$ [48]. These associations, however, are not necessarily proof of causality, and, as the same group later suggested, other $P k d 2 / P k h d 1$-independent pathways could be responsible for the phenotype [49].

Additional support for a $P k d 1 / P k d 2 / P k h d 1$ "cystogenic network" comes from models of autosomal dominant polycystic liver disease (ADPLD). Caused by mutations in PRKCSH or SEC63, isolated ADPLD is characterized by an ADPKD-like liver phenotype without kidney cysts [50,51]. Using conditional knockout and/or transgenic mice of Prkcsk, Sec63, $P k d 1, P k d 2$ and $P k h d 1$, Fedeles et al. showed that ADPLD mouse models have late-onset mild PKD that can be aggravated by heterozygous $P k d l$ or $P k d 2$ inactivation, or homozygous $P k h d l$ deletion; furthermore, partial rescue by $P k d l$ overexpression suggests that $P k d l$ dosage is an important factor in cyst formation/growth [52].

These studies offer hypothesis-driven network models for PKD. An alternative way of addressing the same problem is by perturbing genes involved in PKD and applying bioinformatics tools to build gene networks. We have recently concluded a study along these lines, analyzing over 70 kidney samples using $P k d l$ conditional mice [53]. Our data suggest that gene networks in mutant and control samples are not that dissimilar, which would imply that disease status is conferred by differential activation of conserved transcriptional programs. This interpretation has relevant implications: 1) drug therapies globally targeting broad pathways (such as anti-proliferative or broad kinase inhibitors), though potentially capable of halting disease progression, are unlikely to target mutant cells specifically, and may therefore result in prohibitively high levels of unwanted effects; 2) early cysts in ADPKD kidneys are probably not lined with dedifferentiated, immature cells, and it is therefore conceivable that cystic tubes in the early stages of cystic transformation may be made to revert back to normal. We also showed that Hnf4a is a disease modifier, which 
could have two not mutually exclusive explanations: 1) Hnf4a regulates the expression of disease modifier genes; 2) Hnf4a is a modifier/marker of altered metabolic status, which is itself the modifier. A recent report suggests metabolic pathways in PKD may in fact be dysregulated and future therapies may be able to exploit these differences [54].

It is a truism to say that everything in biology is information processing. Yet, by looking at PKD from an information-flow perspective, one can reframe the question of understanding and curing PKD as figuring out which information is being lost. In this context, a network approach to PKD provides the framework to understand how subtle differences in gene expression and pathway transduction compound to produce phenotypes, allowing the proposal of combination therapies without a "magic bullet" design, thereby accomplishing normal information processing through alternative pathways. This goal can only be met by intensive perturbations of network systems using various cellular and animal models.

\section{Concluding Comments}

Over the last two decades, we went from not knowing which genes caused PKD to being able to systematically dissect different causes, identify abnormal signaling pathways and test therapies. In large measure, mouse models brought about this progress. And though several open questions remain, one can be optimistic that technological advances will keep expanding the horizon of answerable questions.

And yet, there are important caveats that the community should keep in mind. As highlighted in a recent commentary in Nature [55], a commitment to model diseases using a handful of species has the advantage of providing a common language to investigators, but at the potential cost of shunning alternative models that could be more useful in specific cases. Put differently: one should identify the questions that really need to be answered and use the models that accomplish that, rather than finding the questions that the usual model can answer. But finally, no matter which model one chooses, extrapolating to human disease is bound to be tricky; after all, people aren't big mice missing tails.

\section{Acknowledgments}

The authors are supported by the NIDDK Intramural Research Program (ZIA DK075042).

\section{References}

1. Bradley A, et al. The mammalian gene function resource: the international knockout mouse consortium. Mamm Genome. 2012; 23(9-10):580-586. [PubMed: 22968824]

2. McMahon MA, et al. Gene editing: not just for translation anymore. Nat Methods. 2012; 9(1):2831. [PubMed: 22205513]

3. Nardella C, et al. The APL paradigm and the "co-clinical trial" project. Cancer Discov. 2011; 1(2): 108-116. [PubMed: 22116793]

4. Torres VE, et al. Tolvaptan in Patients with Autosomal Dominant Polycystic Kidney Disease. N Engl J Med. 2012; 367(25):2407-2018. [PubMed: 23121377]

5. Gallagher AR, Germino GG, Somlo S. Molecular advances in autosomal dominant polycystic kidney disease. Adv Chronic Kidney Dis. 2010; 17(2):118-130. [PubMed: 20219615]

6 . $\mathrm{Lu} \mathrm{W}$, et al. Comparison of Pkd1-targeted mutants reveals that loss of polycystin-1 causes cystogenesis and bone defects. Hum Mol Genet. 2001; 10(21):2385-2396. [PubMed: 11689485] 
7. Boulter C, et al. Cardiovascular, skeletal, and renal defects in mice with a targeted disruption of the Pkd1 gene. Proc Natl Acad Sci U S A. 2001; 98(21):12174-12179. [PubMed: 11593033]

8. Wu G, et al. Cardiac defects and renal failure in mice with targeted mutations in Pkd2. Nat Genet. 2000; 24(1):75-78. [PubMed: 10615132]

9. Pennekamp P, et al. The ion channel polycystin-2 is required for left-right axis determination in mice. Curr Biol. 2002; 12(11):938-943. [PubMed: 12062060]

10. $\mathrm{Lu} \mathrm{W}$, et al. Late onset of renal and hepatic cysts in Pkd1-targeted heterozygotes. Nat Genet. 1999; 21(2):160-161. [PubMed: 9988265]

11. Yoshiba S, et al. Cilia at the node of mouse embryos sense fluid flow for left-right determination via Pkd2. Science. 2012; 338(6104):226-231. [PubMed: 22983710]

12. Wu G, et al. Somatic inactivation of Pkd2 results in polycystic kidney disease. Cell. 1998; 93(2): 177-188. [PubMed: 9568711]

13. Garcia-Gonzalez MA, et al. Pkd1 and Pkd2 are required for normal placental development. PLoS One. 2010; 5(9):e12821. [PubMed: 20862291]

14. Piontek K, et al. A functional floxed allele of Pkd1 that can be conditionally inactivated in vivo. J Am Soc Nephrol. 2004; 15(12):3035-3043. [PubMed: 15579506]

15. Piontek K, et al. A critical developmental switch defines the kinetics of kidney cyst formation after loss of Pkd1. Nat Med. 2007; 13(12):1490-1495. [PubMed: 17965720]

16. Grantham JJ, et al. Evidence of extraordinary growth in the progressive enlargement of renal cysts. Clin J Am Soc Nephrol. 2010; 5(5):889-896. [PubMed: 20360307]

17. Rossetti $S$, et al. Incompletely penetrant PKD1 alleles suggest a role for gene dosage in cyst initiation in polycystic kidney disease. Kidney Int. 2009; 75(8):848-855. [PubMed: 19165178]

18. Hopp K, et al. Functional polycystin-1 dosage governs autosomal dominant polycystic kidney disease severity. J Clin Invest. 2012; 122(11):4257-4273. [PubMed: 23064367]

19. Serra AL, et al. Sirolimus and kidney growth in autosomal dominant polycystic kidney disease. $\mathrm{N}$ Engl J Med. 2010; 363(9):820-829. [PubMed: 20581391]

20. Walz G, et al. Everolimus in patients with autosomal dominant polycystic kidney disease. N Engl J Med. 2010; 363(9):830-840. [PubMed: 20581392]

21. Hogan MC, et al. Randomized clinical trial of long-acting somatostatin for autosomal dominant polycystic kidney and liver disease. J Am Soc Nephrol. 2010; 21(6):1052-1061. [PubMed: 20431041]

22. Shillingford J, et al. The mTOR pathway is regulated by polycystin-1, and its inhibition reverses renal cystogenesis in polycystic kidney disease. Proc Natl Acad Sci U S A. 2006; 103(14):54665471. [PubMed: 16567633]

23. Masyuk TV, et al. Pasireotide is more effective than Octreotide in reducing hepato-renal cystogenesis in rodents with polycystic kidney and liver diseases. Hepatology. 2012 [Epub ahead of print]. PMID: 23172758.

24. Watnick T, Germino GG. mTOR inhibitors in polycystic kidney disease. N Engl J Med. 2010; 363(9):879-881. [PubMed: 20581393]

25. Olbrich H, et al. Mutations in a novel gene, NPHP3, cause adolescent nephronophthisis, tapetoretinal degeneration and hepatic fibrosis. Nat Genet. 2003; 34(4):455-459. [PubMed: 12872122]

26. Brown JH, et al. Missense mutation in sterile alpha motif of novel protein SamCystin is associated with polycystic kidney disease in (cy/+) rat. J Am Soc Nephrol. 2005; 16(12):3517-3526. [PubMed: 16207829]

27. Dwan K, et al. Systematic review of the empirical evidence of study publication bias and outcome reporting bias. PLoS One. 2008; 3(8):e3081. [PubMed: 18769481]

28. Scott $S$, et al. Design, power, and interpretation of studies in the standard murine model of ALS. Amyotroph Lateral Scler. 2008; 9(1):4-15. [PubMed: 18273714]

29. Guay-Woodford LM, Desmond RA. Autosomal recessive polycystic kidney disease: the clinical experience in North America. Pediatrics. 2003; 111(5 Pt 1):1072-1080. [PubMed: 12728091]

30. Nagasawa Y, et al. Identification and characterization of Pkhd1, the mouse orthologue of the human ARPKD gene. J Am Soc Nephrol. 2002; 13(9):2246-2258. [PubMed: 12191969] 
31. Onuchic LF, et al. PKHD1, the polycystic kidney and hepatic disease 1 gene, encodes a novel large protein containing multiple immunoglobulin-like plexin-transcription-factor domains and parallel beta-helix 1 repeats. Am J Hum Genet. 2002; 70(5):1305-1317. [PubMed: 11898128]

32. Ward CJ, et al. The gene mutated in autosomal recessive polycystic kidney disease encodes a large, receptor-like protein. Nat Genet. 2002; 30(3):259-269. [PubMed: 11919560]

33. Moser M, et al. A mouse model for cystic biliary dysgenesis in autosomal recessive polycystic kidney disease (ARPKD). Hepatology. 2005; 41(5):1113-1121. [PubMed: 15830394]

34. Gallagher A, et al. Biliary and pancreatic dysgenesis in mice harboring a mutation in Pkhd1. Am J Pathol. 2008; 172(2):417-429. [PubMed: 18202188]

35. Woollard JR, et al. A mouse model of autosomal recessive polycystic kidney disease with biliary duct and proximal tubule dilatation. Kidney Int. 2007; 72(3):328-336. [PubMed: 17519956]

36. Garcia-Gonzalez M, et al. Genetic interaction studies link autosomal dominant and recessive polycystic kidney disease in a common pathway. Hum Mol Genet. 2007; 16(16):1940-1950. [PubMed: 17575307]

37. Williams SS, et al. Kidney cysts, pancreatic cysts, and biliary disease in a mouse model of autosomal recessive polycystic kidney disease. Pediatr Nephrol. 2008; 23(5):733-741. [PubMed: 18286309]

38. Kim I, et al. Fibrocystin/polyductin modulates renal tubular formation by regulating polycystin-2 expression and function. J Am Soc Nephrol. 2008; 19(3):455-468. [PubMed: 18235088]

39. Bakeberg JL, et al. Epitope-tagged Pkhd1 tracks the processing, secretion, and localization of fibrocystin. J Am Soc Nephrol. 2011; 22(12):2266-2277. [PubMed: 22021705]

40. Mrug M, et al. Kinesin family member 12 is a candidate polycystic kidney disease modifier in the cpk mouse. J Am Soc Nephrol. 2005; 16(4):905-916. [PubMed: 15728779]

41. Takakura A, et al. Renal injury is a third hit promoting rapid development of adult polycystic kidney disease. Hum Mol Genet. 2009; 18(14):2523-2531. [PubMed: 19342421]

42. Happé $\mathrm{H}$, et al. Toxic tubular injury in kidneys from Pkd1-deletion mice accelerates cystogenesis accompanied by dysregulated planar cell polarity and canonical Wnt signaling pathways. Hum Mol Genet. 2009; 18(14):2532-2542. [PubMed: 19401297]

43. Upadhya $P$, et al. Mutations in a NIMA-related kinase gene, Nek1, cause pleiotropic effects including a progressive polycystic kidney disease in mice. Proc Natl Acad Sci U S A. 2000; 97(1): 217-221. [PubMed: 10618398]

44. Thiel C, et al. NEK1 mutations cause short-rib polydactyly syndrome type majewski. Am J Hum Genet. 2011; 88(1):106-114. [PubMed: 21211617]

45. Liu S, et al. A defect in a novel Nek-family kinase causes cystic kidney disease in the mouse and in zebrafish. Development. 2002; 129(24):5839-5846. [PubMed: 12421721]

46. Otto EA, et al. NEK8 mutations affect ciliary and centrosomal localization and may cause nephronophthisis. J Am Soc Nephrol. 2008; 19(3):587-592. [PubMed: 18199800]

47. Menezes L, Germino G. Polycystic kidney disease, cilia, and planar polarity. Methods Cell Biol. 2009; 94:273-297. [PubMed: 20362096]

48. Gresh L, et al. A transcriptional network in polycystic kidney disease. EMBO J. 2004; 23(7):16571668. [PubMed: 15029248]

49. Ma Z, et al. Mutations of HNF-1beta inhibit epithelial morphogenesis through dysregulation of SOCS-3. Proc Natl Acad Sci U S A. 2007; 104(51):20386-20391. [PubMed: 18077349]

50. Davila S, et al. Mutations in SEC63 cause autosomal dominant polycystic liver disease. Nat Genet. 2004; 36(6):575-577. [PubMed: 15133510]

51. Li A, et al. Mutations in PRKCSH cause isolated autosomal dominant polycystic liver disease. Am J Hum Genet. 2003; 72(3):691-703. [PubMed: 12529853]

52. Fedeles SV, et al. A genetic interaction network of five genes for human polycystic kidney and liver diseases defines polycystin-1 as the central determinant of cyst formation. Nat Genet. 2011; 43(7):639-647. [PubMed: 21685914]

53. Menezes LF, et al. Network Analysis of a Pkd1-Mouse Model of Autosomal Dominant Polycystic Kidney Disease Identifies HNF4a as a Disease Modifier. PLoS Genet. 2012; 8(11):e1003053. [PubMed: 23209428] 
54. Rowe, et al. Defective glucose metabolism in polycystic kidney disease identifies a new therapeutic strategy. Nat Med. 2013; 19(4):488-493. [PubMed: 23524344]

55. Bolker J. Model organisms: There's more to life than rats and flies. Nature. 2012; 491(7422):3133. [PubMed: 23128209]

56. Gattone VH, et al. Developmental expression of urine concentrationassociated genes and their altered expression in murine infantile-type polycystic kidney disease. Dev Genet. 1999; 24(3-4): 309-318. [PubMed: 10322639]

57. Torres V, et al. Effective treatment of an orthologous model of autosomal dominant polycystic kidney disease. Nat Med. 2004; 10(4):363-364. [PubMed: 14991049]

58. Gattone $\mathrm{VH}$, et al. Inhibition of renal cystic disease development and progression by a vasopressin V2 receptor antagonist. Nat Med. 2003; 9(10):1323-1326. [PubMed: 14502283]

59. Wang X, et al. Effectiveness of vasopressin V2 receptor antagonists OPC-31260 and OPC-41061 on polycystic kidney disease development in the PCK rat. J Am Soc Nephrol. 2005; 16(4):846851. [PubMed: 15728778]

60. Masyuk TV, et al. Octreotide inhibits hepatic cystogenesis in a rodent model of polycystic liver disease by reducing cholangiocyte adenosine 3',5'-cyclic monophosphate. Gastroenterology. 2007; 132(3):1104-1116. [PubMed: 17383431]

61. Hogan MC, et al. Randomized clinical trial of long-acting somatostatin for autosomal dominant polycystic kidney and liver disease. J Am Soc Nephrol. 2010; 21(6):1052-1061. [PubMed: 20431041]

62. Tao Y, et al. Rapamycin markedly slows disease progression in a rat model of polycystic kidney disease. J Am Soc Nephrol. 2005; 16(1):46-51. [PubMed: 15563559]

63. Zafar I, et al. Long-term rapamycin therapy in the Han:SPRD rat model of polycystic kidney disease (PKD). Nephrol Dial Transplant. 2009; 24(8):2349-2353. [PubMed: 19321761]

64. Wahl PR, et al. Inhibition of mTOR with sirolimus slows disease progression in Han:SPRD rats with autosomal dominant polycystic kidney disease (ADPKD). Nephrol Dial Transplant. 2006; 21(3):598-604. [PubMed: 16221708]

65. Shillingford J, et al. Rapamycin ameliorates PKD resulting from conditional inactivation of Pkd1. J Am Soc Nephrol. 2010; 21(3):489-497. [PubMed: 20075061] 


\section{Table 1}

Mouse models used in PKD pre-clinical trials.

\begin{tabular}{|c|c|c|c|}
\hline Drug & Effect & Model & Clinical Trial \\
\hline OPC-31260 & $\begin{array}{l}\text { Lowers cAMP } \\
\text { (antagonist of } \\
\text { Vasopressin } 2 \\
\text { Receptor, VPV2R) }\end{array}$ & $\begin{array}{l}c p k \text { mouse (non-ortholgous } \\
\text { ARPKD model) [56] Mouse } \\
\text { orthologous } P k d 2\left(P k d 2^{-/ W S 25}\right) \\
\text { [57]. } \\
\text { PCK rat (frameshit in exon } 36 \text { of } \\
P k h d 1 \text { rat ortholog) [58] } p c y \\
\text { mouse (missense mutation in the } \\
\text { nephronophtisis gene } N p h 3) \text { [58] }\end{array}$ & \\
\hline Tolvaptan (OPC-41061) & $\begin{array}{l}\text { Lowers cAMP } \\
\text { (antagonist of } \\
\text { VPV2R); derived } \\
\text { from OPC-31260 }\end{array}$ & PCK rat [59] & $\begin{array}{l}\text { TEMPO }(1,445 \text { patients; slower rate of } \\
\text { cyst growth in drug group: } 5.5 \% \text { per year } \\
\text { versus } 2.8 \% \text { per year; } P<0.001 \text { and slower } \\
\text { decline in kidney function (reciprocal of } \\
\text { the serum creatinine level, }-2.61 \mathrm{mg} \cdot \mathrm{ml}^{-1} \\
\text { per year vs. }-3.81 \mathrm{mg} \cdot \mathrm{ml}^{-1} \text { per year; } \\
\mathrm{P}<0.001))[4]\end{array}$ \\
\hline Octreotide (somatostatin analogue) & Lowers cAMP & PCK rat $[60]$ & $\begin{array}{l}42 \text { patients with polycystic liver and } \\
\text { kidney disease (liver volume changed } \\
4.95 \% \pm 6.77 \% \text { in the octreotide group } \\
\text { compared to }(0.92 \% \pm 8.33 \%) \text { in the } \\
\text { placebo group }(P=0.048 \text {, rank-sum test); } \\
\text { no difference in kidney function [61] }\end{array}$ \\
\hline Pasireotide (somatostatin analogue) & Lowers cAMP & $\begin{array}{l}\text { PCK rat and } P k d 2^{-/ W S 25} \text { mouse } \\
\text { [23] }\end{array}$ & \\
\hline Sirulimus (Rapamycin)/Everolimus & mTOR inhibitor & $\begin{array}{l}\text { Han:SPRD rat (non-orthologous } \\
\text { ADPKD model) [62-64] } \\
P k d 1^{\text {cond/cond:Nestin }} \text { cre mouse } \\
\text { model (mosaic, random, kidney } \\
\text { inactivation) [65] Tg737 } \text { orpklorpk; } \\
T g R s q \text { (non-orthologous polaris } \\
\text { mouse model) and bpk (non- } \\
\text { orthologous Bicaudal-C mouse } \\
\text { model) [22] }\end{array}$ & $\begin{array}{l}433 \text { patients with ADPKD (reduction in } \\
\text { the rate of increase in kidney volume: } \\
\text { least-square mean differences between } \\
\text { everolimus and placebo groups were } 54 \\
\text { ml at } 1 \text { year }(\mathrm{P}=0.02) \text { and } 71 \mathrm{ml} \text { at } 2 \text { years } \\
(\mathrm{P}=0.06) \text {; everolimus group had a greater } \\
\text { decline in the estimated GFR (by } 5.4 \mathrm{ml} \\
\text { per minute) than placebo (with a decline } \\
\text { of } 3.2 \mathrm{ml} \text { per minute) }(\mathrm{P}=0.004) \text { [20]. } 100 \\
\text { ADPKD patients in early stages of chronic } \\
\text { kidney disease (sirolimus group had no } \\
\text { difference in rate of kidney growth [19]) }\end{array}$ \\
\hline
\end{tabular}

